\title{
Value of sarcopenia assessed by computed tomography for the prediction of postoperative morbidity following oncological colorectal resection
}

Citation for published version (APA):

van der Kroft, G., Bours, M. J. L., Janssen-Heijnen, M., van Berlo, C. L. H., \& Konsten, J. L. M. (2018). Value of sarcopenia assessed by computed tomography for the prediction of postoperative morbidity following oncological colorectal resection: A comparison with the malnutrition screening tool. Clinical Nutrition ESPEN, 24, 114-119. https://doi.org/10.1016/j.clnesp.2018.01.003

Document status and date:

Published: 01/04/2018

DOI:

10.1016/j.clnesp.2018.01.003

Document Version:

Publisher's PDF, also known as Version of record

Document license:

Taverne

Please check the document version of this publication:

- A submitted manuscript is the version of the article upon submission and before peer-review. There can be important differences between the submitted version and the official published version of record.

People interested in the research are advised to contact the author for the final version of the publication, or visit the DOI to the publisher's website.

- The final author version and the galley proof are versions of the publication after peer review.

- The final published version features the final layout of the paper including the volume, issue and page numbers.

Link to publication

\footnotetext{
General rights rights.

- You may freely distribute the URL identifying the publication in the public portal. please follow below link for the End User Agreement:

www.umlib.nl/taverne-license

Take down policy

If you believe that this document breaches copyright please contact us at:

repository@maastrichtuniversity.nl

providing details and we will investigate your claim.
}

Copyright and moral rights for the publications made accessible in the public portal are retained by the authors and/or other copyright owners and it is a condition of accessing publications that users recognise and abide by the legal requirements associated with these

- Users may download and print one copy of any publication from the public portal for the purpose of private study or research.

- You may not further distribute the material or use it for any profit-making activity or commercial gain

If the publication is distributed under the terms of Article $25 \mathrm{fa}$ of the Dutch Copyright Act, indicated by the "Taverne" license above, 
Original article

\title{
Value of sarcopenia assessed by computed tomography for the prediction of postoperative morbidity following oncological colorectal resection: A comparison with the malnutrition screening tool
}

\author{
G. van der Kroft ${ }^{\text {a, }}$, Dr M.J.L. Bours ${ }^{\text {b }}$, Dr M. Janssen-Heijnen ${ }^{\text {b, c }}$, Dr C.L.H. van Berlo ${ }^{\text {d, }}$ \\ Dr J.L.M. Konsten ${ }^{\mathrm{d}}$ \\ a Department of General, Gastrointestinal and Transplant Surgery, Uniklinik Aachen, Aachen, Germany \\ b Department of Epidemiology, GROW - School for Oncology and Developmental Biology, Maastricht University, Maastricht, The Netherlands \\ ${ }^{c}$ Department of Clinical Epidemiology, VieCuri Medical Centre, Venlo, The Netherlands \\ d Department of Surgery, VieCuri Medical Centre Centre, Venlo, The Netherlands
}

\section{A R T I C L E I N F O}

\section{Article history:}

Received 31 May 2017

Accepted 9 January 2018

\section{Keywords:}

Sarcopenia

Malnutrition Universal Screening Tool

Malnutrition

Nutritional risk

Colorectal cancer

Colorectal resection

Postoperative complications

Morbidity

\begin{abstract}
S U M M A R Y
Background: Computed tomography (CT) can be used for accurate estimation of whole-body muscle mass and muscle density and for detection of sarcopenia. The goal of this study was to evaluate the additional value of CT measured sarcopenia and muscle attenuation alongside the Malnutrition Universal Screening Tool (MUST) for the prediction of post-operative morbidity after oncological colorectal resection, whilst correcting for known risk factors.

Methods: A prospective cohort study of 80 patients undergoing elective colorectal surgery in the Netherlands. Patients were screened for nutritional risk upon admission using the MUST. Additionally, preoperative CT scans were used to determine skeletal muscle mass for the detection of sarcopenia and muscle attenuation. Univariate and multivariable analyses were performed to evaluate associations between the MUST, muscle attenuation and sarcopenia on the one hand and post-operative complications measured by the Clavien-Dindo score on the other hand.

Results: American Society of Anesthesiology-classification (ASA) $\geq 3$, age $\geq 70$, MUST $\geq 2$ and lower than median muscle attenuation were significantly associated with a higher risk for postoperative complications (Clavien-Dindo score $\geq 2)(p \leq 0.05)$, whereas sarcopenia was not $(p=0.59)$. Multivariate analyses showed that only MUST $\geq 2$ remained significantly associated with postoperative complications when corrected for age ( $p=0.03$, OR $5.8,95 \% \mathrm{CI} 1.1-29.6)$, but not when corrected for age $\geq 70$ and ASA $\geq 3$. Muscle attenuation and sarcopenia were not significantly associated with postoperative complications.

Conclusion: Our results suggest that using CT measured sarcopenia may have only little additional value over the MUST for the prediction of increased short-term post-operative morbidity after oncological colorectal surgery. It also underlines the importance of currently implemented easy-to-use nutritional screening tools (MUST) and raises the question of the evaluation of muscle quality versus quantity in body composition imaging. However, further research is needed to investigate the role of sarcopenia for predicting outcome after colorectal surgery, and investigate the role of muscle attenuation measurements for the prediction of muscle function.

Category of submission: observational study.
\end{abstract}

๑) 2018 European Society for Clinical Nutrition and Metabolism. Published by Elsevier Ltd. All rights reserved.

\footnotetext{
* Corresponding author. Sekretariat Klinik für Allgemein-, Visceral- und Transplantationschirurgie, Universitätsklinikum Aachen, Pauwelsstraße 30, 52074 Aachen, Germany. Fax: +49 (0) 2418082417.
}

E-mail address: Gregory.kroft@gmail.com (G. van der Kroft).

\section{Introduction and rationale}

In the Netherlands, colorectal cancer (CRC) constitutes the second most common type of malignant disease. According to statistics from the population-based Netherlands Cancer Registry almost 
15,600 new cases of CRC were diagnosed in the Netherlands in 2015 (almost 8900 men and almost 6700 women). A general epidemiological trend in CRC shows an increase in incidence over time, increased incidence with age and decreasing mortality [1].

Nutritional status has been shown to be an independent risk factor for post-operative complications amongst all patients undergoing colorectal resection [2-5]. Typical measures used to screen for and assess malnutrition include dietary intake and changes in body mass index (BMI). Nutritional screening tools that use these parameters have been shown to be useful for the identification of individuals at nutritional risk [6-8]. The European Society for Clinical Nutrition and Metabolism (ESPEN) recommends the use of the Malnutrition Universal Screening Tool (MUST) for clinical use [6]. Nutritional screening tools have been shown to be independent risk predictors for post-operative complications [2-5]. Recently, the use of computed tomography (CT) has been suggested to be a reliable tool for accurate estimation of whole-body muscle mass and the detection of sarcopenia [9-15], although not all evidence unequivocally supports this [16-18]. This technique uses CT images at the level of the third lumbar vertebra (L3) to determine cross-sectional area of skeletal muscle at L3, which when corrected for the patient's height is a measure of lean body mass [9,19]. Besides estimation of body mass, e.g. for the detection of sarcopenia, CT image analysis has been used for the estimation of muscle density, also known as muscle attenuation. Muscle attenuation measures the mean value of Hounsfield units in skeletal muscle mass at the L3 level, and may possibly be used for the estimation of muscle function, rather than muscle mass [20].

This direct quantification of lean body mass and muscle attenuation offers a potentially objective measure of patients' body composition and potential loss of functional muscle mass. The goal of this study was to assess whether CT sarcopenia screening has additional value besides the MUST for the prediction of postoperative complications after oncological colorectal resection.

\section{Study design \& methods}

A prospective cohort study of patients undergoing elective surgical intervention was conducted. All patients aged 18 years and older undergoing elective oncological colorectal resection between October 2012 and July 2013 for the treatment of colon and rectal cancer in VieCuri teaching hospital in the south of the Netherlands were included $(\mathrm{N}=80)$. Patients with American Society of Anesthesiology (ASA)-classification V, severe liver cirrhosis - Child grade $C$, end stage renal disease requiring dialysis, severe heart disease - New York Heart Association class IV and chronic obstructive pulmonary disease (COPD) requiring (home)oxygen therapy or an interval greater than 2 months between the time of the scan and the operation were excluded $(\mathrm{N}=6)$.

Prior to this study, a nutritional screening and intervention algorithm had successfully been implemented at our hospital in accordance with ESPEN guidelines. All patients were screened using the MUST screening tool upon hospital admission. Patients with MUST scores of 2 or higher received a nutritional intervention in the form of additional high caloric food products before surgery, in accordance with ESPEN guidelines. As a nutritional screening and treatment algorithm was already in place, no change in the nutritional intervention regime was implemented in this study.

Patients with rectal carcinoma underwent neoadjuvant therapy for a period of 8 weeks, followed by a restaging CT and then surgery within 2 weeks in accordance with dutch guidelines. Colon carcinoma patients did not receive neoadjuvant treatment. For the purpose of this study, the restaging CT was used for sarcopenia measurements.
Besides nutritional status, known risk factors for post-operative complications were recorded: age ( $<70$ and $\geq 70$ years), ASAclassification ( $<3$ and $\geq 3$ ), stage of disease (1-4), planned type of procedure (laparoscopic or open: conversion from laparoscopic to open surgery was classified as open surgery) and peri-operative blood transfusion. Comorbid diseases were categorized according to the Charlson Comorbidity Index. In the Charlson Comorbidity index, a weighted score is assigned to each of 17 comorbidities and the sum of the index score is an indicator of disease burden and an estimator of mortality. For the analyses we classified the Charlson index as a binary variable; a score of 3 or more was considered an increased comorbidity risk [21].

The primary endpoint was the occurrence of post-operative complications within 30 days after surgery, which were prospectively registered. Post-operative complications were categorized by severity as proposed by Clavien-Dindo [22]. According to this classification, complications are defined as any deviation from the normal post-operative course. Complications were graded from I to $\mathrm{V}$, based on the extent of intervention needed to correct the complication. In the case of several complications these were recorded separately, and the most severe complication was used in the statistical analyses. For the statistical analyses, we classified postoperative complications as a binary outcome: complications graded 2 or higher were categorized as the occurrence of serious post-operative complications, whereas grade 0 and 1 were graded as no serious complications.

Data from this cohort has previously been used for a different study [23].

\section{CT measured sarcopenia}

Pre-operative abdominal CT scans were available for all patients $(\mathrm{N}=80)$. Exclusion was on the basis of poor quality of CT scans $(\mathrm{N}=5)$, scans not showing the abdominal wall $(\mathrm{N}=4)$, absence of the third lumber vertebra on the scan $(\mathrm{N}=2)$, and/or an interval greater than 2 months between the time of the scan and the operation $(\mathrm{N}=6)$.

Muscle mass was measured by analyses of electronically stored CT images, which had been routinely taken for diagnostic purposes. The third lumbar vertebra (L3) was used as a standard landmark to measure muscle cross-sectional area in $\mathrm{cm}^{2}$. Skeletal muscle tissue was identified and quantified on CT images by means of Hounsfield unit (HU) thresholds $(-29$ to $+150 \mathrm{HU})$. The total cross-sectional area of skeletal muscles at L3 was computed by use of Slice-Omatic software, version 5.0 (Tomovision, Montreal, QC, Canada) (Fig. 1). Total muscle area at L3 normalized for body height (L3 skeletal muscle index, $\mathrm{cm}^{2} / \mathrm{m}^{2}$ ) is linearly related to whole-body muscle mass. Based on the L3 skeletal muscle index, sarcopenia was defined using sex-specific cutpoints: $43 \mathrm{~cm}^{2} / \mathrm{m}^{2}$ for males with BMI $<25.0 \mathrm{~kg} / \mathrm{m}^{2}$ and $53 \mathrm{~cm}^{2} / \mathrm{m}^{2}$ for males with BMI $\geq 25.0 \mathrm{~kg} / \mathrm{m}^{2}$; the cutpoint for sarcopenia in females was $41 \mathrm{~cm}^{2} / \mathrm{m}^{2}$, irrespective of BMI $[24,25]$. Besides muscle mass, muscle radiation attenuation (i.e. the mean $\mathrm{HU}$ of muscle tissue) was also determined as an indicator of muscle density. Study participants were divided in groups of high versus low muscle attenuation based on the median value as cutoff (low: <34.1 HU; high: $\geq 34.1 \mathrm{HU}$ ).

\section{Statistical analyses}

Frequencies are presented as absolute numbers and percentages. Univariate analyses were used to determine the association between each individual variable and the outcome variable using Chi-square analysis or Fisher's Exact test and or likelihood ratio test in case of low expected frequencies. $\mathrm{P}=<0.05$ was considered significant. 


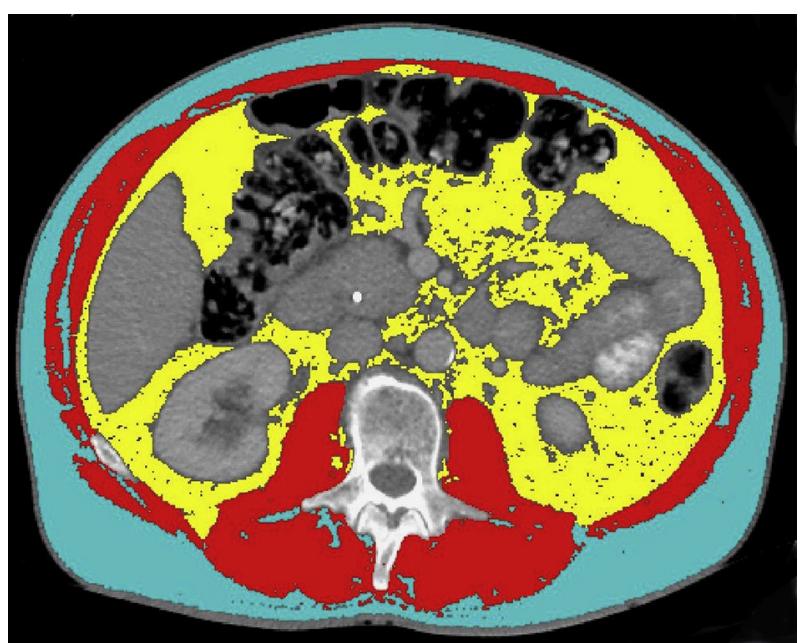

Fig. 1. Segmented CT image at the L3 level showing subcutaneous fat in blue, muscle in red, and visceral fat in yellow.

\subsection{Multivariable analyses}

Confounding between sex, age $(<70$ and $\geq 70)$, ASAclassification ( $<3$ and $\geq 3$ ) and MUST and CT-measured sarcopenia was tested by consecutively evaluating them in our multivariate model. Multiple logistic regression analysis was used to analyse the independent association between our primary study variables and the occurrence of post-operative complications (yes versus no). Only variables with a significant association in univariate analyses were included in multivariable analyses. Due to limited statistical power allowing for a limited number of variables to be included in our multivariable model, we opted to run several multivariable models, i.e., an uncorrected model containing the primary study variables and four models correcting for other risk factors. The first model only included the two main variables of our study (MUST and sarcopenia). The second contained muscle attenuation instead of sarcopenia. In the third model, age (age $\geq 70$ ) was added. The fourth and final model contained both the primary study variables with the addition of age and ASA $\geq 3$. All statistical analyses were performed by using SPSS version 20.0.

\section{Results}

Of the 80 included patients, a total of 63 were selected for CT analysis, of whom $64 \%$ were male. The mean time between CT and operation was 20 days. The mean age was 69 years (SD 10.5) and $48 \%$ of patients were aged seventy years or older. Seventy-three $73 \%(n=46)$ of patients suffered from colon carcinoma and $27 \%$ $(\mathrm{n}=16)$ from rectal carcinoma. Fifty-two percent of patients were sarcopenic before surgery $(n=33)$. Of the colon and rectal resection groups, respectively $57 \%(n=26)$ and $44 \%(n=9)$ were sarcopenic. Eighteen patients suffered stage 1 (28\%), 13 patients stage $2(21 \%)$, 20 stage 3 (32\%) and 12 patients stage 4 (19\%) tumors. Five percent had a BMI higher than $30 \mathrm{~kg} / \mathrm{m}^{2}(\mathrm{~N}=3)$, of which one was sarcopenic. The mean BMI was $26 \mathrm{~kg} / \mathrm{m}^{2}$. Sixteen percent had a MUST score of 2 or higher $(\mathrm{N}=10)$. Eleven percent of patients had an ASAclassification of three or higher $(\mathrm{N}=7)$. Forty-four percent $(\mathrm{N}=26)$ underwent open surgery and $56 \%(\mathrm{~N}=27)$ underwent laparoscopic surgery, of which $9 \%(\mathrm{~N}=3)$ converted to an open procedure. Twenty-five percent $(\mathrm{N}=16)$ received packed cells perioperatively. Twenty-one percent of patients $(\mathrm{N}=16)$ had a Charlson index of 3 or higher. Sarcopenic patients had higher MUST scores, however this was not signifficant $(\mathrm{p}=0.06)$ (Table 1$)$.
Table 1

Division of study variables in sarcopenic and non-sarcopenic groups.

\begin{tabular}{|c|c|c|c|}
\hline Study parameters & $\begin{array}{l}\text { Sarcopenia } \\
\text { no }(n=30)\end{array}$ & $\begin{array}{l}\text { Sarcopenia yes } \\
(\mathrm{n}=33)\end{array}$ & P-value \\
\hline Muscle Attenuation (HU) & & & 0.00 \\
\hline$<$ median & $7(23 \%)$ & $24(77 \%)$ & \\
\hline$\geq$ median & $23(72 \%)$ & $9(28 \%)$ & \\
\hline Muscle area $\left(\mathrm{CM}^{2}\right)$ & & & 0.00 \\
\hline$<$ median & $8(24 \%)$ & $25(66 \%)$ & \\
\hline$\geq$ median & $22(73 \%)$ & $8(27 \%)$ & \\
\hline$\overline{M U S T}$ & & & 0.06 \\
\hline$<2$ & $28(53 \%)$ & $25(47 \%)$ & \\
\hline$\geq 2$ & $2(20 \%)$ & $8(80 \%)$ & \\
\hline Perioperative transfusion & & & 0.13 \\
\hline no & $25(53 \%)$ & $22(47 \%)$ & \\
\hline yes & $5(31 \%)$ & $11(69 \%)$ & \\
\hline Age groups & & & 0.25 \\
\hline$<70$ & $18(55 \%)$ & $15(45 \%)$ & \\
\hline$\geq 70$ & $12(40 \%)$ & $18(60 \%)$ & \\
\hline$\overline{\text { ASA }}$ & & & 0.43 \\
\hline$<3$ & $28(50 \%)$ & $28(50 \%)$ & \\
\hline$\geq 3$ & $2(29 \%)$ & $5(71 \%)$ & \\
\hline Charlson & & & 0.46 \\
\hline$<3$ & $25(50 \%)$ & $25(50 \%)$ & \\
\hline$\geq 3$ & $5(39 \%)$ & $8(61 \%)$ & \\
\hline BMI groups & & & 0.60 \\
\hline$<30$ & $28(47 \%)$ & $32(53 \%)$ & \\
\hline$\geq 30$ & $2(67 \%)$ & $1(33 \%)$ & \\
\hline Sex & & & 0.82 \\
\hline male & $19(49 \%)$ & $20(51 \%)$ & \\
\hline female & $11(46 \%)$ & $13(54 \%)$ & \\
\hline Procedure & & & 0.84 \\
\hline laparoscopic & 18 (49\%) & $19(51 \%)$ & \\
\hline open & $12(46 \%)$ & $14(54 \%)$ & \\
\hline Tumor Stage & & & 0.97 \\
\hline Stage 1 & $9(50 \%)$ & $9(50 \%)$ & \\
\hline Stage 2 & $6(46 \%)$ & 7 (54\%) & \\
\hline Stage 3 & $10(50 \%)$ & $10(50 \%)$ & \\
\hline Stage 4 & $5(42 \%)$ & $7(58 \%)$ & \\
\hline
\end{tabular}

Division of study variables in sarcopenic and non-sarcopenic groups. P-value calculated by Chi-square, likelihood ratio Test or Fisher's Exact test.

Muscle $\mathrm{CM}^{2}$ was defined as lower or higher than the median (men: $<154.5 \mathrm{~cm}^{2}$ / $\mathrm{m}^{2}$ and $\geq 154.5 \mathrm{~cm}^{2} / \mathrm{m}^{2}$ woman $<103.3 \mathrm{~cm}^{2} / \mathrm{m}^{2}$ and $\geq 103.3 \mathrm{~cm}^{2} / \mathrm{m}^{2}$ ), Muscle attenuation was defined as higher or lower than the media value $(<34.1 \mathrm{HU}$ or $\geq 34.1 \mathrm{HU})$.

Three percent of patients $(\mathrm{N}=2)$ died due to post-operative complications, one of which was sarcopenic before surgery. Thirty-eight percent of patients $(\mathrm{N}=24)$ suffered complications of which the highest grade complication was used for analyses ( $4 \mathrm{x}$ grade $1,7 x$ grade $2,8 x$ grade $3,2 x$ grade $4,2 x$ grade 5 ) (Table 2 ).

Table 2

Registered complications.

\begin{tabular}{lll}
\hline Type of complication & Frequency $\mathrm{n}$ & Clavien-Dindo-Score \\
\hline Anastomotic leakage & 5 & $3 \mathrm{~b}$ \\
Wound infection opened at bedside & 5 & 1 \\
Abdominal sepsis & 4 & $4 \mathrm{a} / \mathrm{b}$ \\
Post-operative ileus & 3 & 2 \\
Pneumonia & 3 & 2 \\
Presacral abcess & 2 & $3 \mathrm{a}$ \\
Urinary tract infections & 2 & 2 \\
Abdominal abcess & 2 & $3 \mathrm{a}$ \\
Line infections & 2 & 2 \\
Ostomy problems & 2 & $3 \mathrm{~b}$ \\
$\quad$ requiring re-operation & 1 & \\
CVA & 1 & 4 \\
Deep Vein Thrombosis & 1 & 2 \\
Bleeding requiring re-operation & 2 & $3 \mathrm{~b}$ \\
Death & $\mathbf{3 5}$ & 5 \\
Total & & \\
\hline
\end{tabular}

Total number of registered complications Clavien-Dindo $\geq 2$. 
Univariate analysis showed that ASA $\geq 3$, age $\geq 70$, MUST $\geq 2$ and lower than median muscle attenuation were significantly associated with a higher risk for postoperative complications (Clavien-Dindo score $\geq 2$ ) ( $p \leq 0.05)$. Sarcopenia was not significant $(\mathrm{p}=0.59)$ (Table 3).

Multivariable analyses showed that MUST $\geq 2(p=0.03$, OR 5.8, 95\%CI 1.1-29.6) remained significantly associated with the occurrence of postoperative complications after adjustment for

Table 3

Univariate analyses of all study parameters on post-operative complications claviendindo score $\geq 2$.

\begin{tabular}{|c|c|c|c|}
\hline & Complication & & P-Value \\
\hline ASA & No $(n=42)$ & Yes $(n=21)$ & $<0.01$ \\
\hline$<3$ & $41(73 \%)$ & $15(27 \%)$ & \\
\hline$\geq 3$ & $1(14 \%)$ & $6(86 \%)$ & \\
\hline Age & & & $<0.01$ \\
\hline$<70$ & $27(82 \%)$ & $6(18 \%)$ & \\
\hline$\geq 70$ & $15(50 \%)$ & $15(50 \%)$ & \\
\hline$\overline{M U S T}$ & & & 0.01 \\
\hline$<2$ & $39(74 \%)$ & $14(26 \%)$ & \\
\hline$\geq 2$ & $3(30 \%)$ & $7(70 \%)$ & \\
\hline$\overline{\text { Muscle Attenuation }}$ & & & 0.05 \\
\hline$<$ Median & $17(55 \%)$ & $14(45 \%)$ & \\
\hline$\geq$ Median & $25(78 \%)$ & $7(22 \%)$ & \\
\hline Perioperative transfusion & & & 0.10 \\
\hline No & $34(73 \%)$ & $13(17 \%)$ & \\
\hline Yes & $8(50 \%)$ & $8(50 \%)$ & \\
\hline Procedure & & & 0.20 \\
\hline Lap & 27 (73\%) & $10(27 \%)$ & \\
\hline Open & $15(56 \%)$ & $11(44 \%)$ & \\
\hline Stage & & & 0.25 \\
\hline 1 & $12(67 \%)$ & $6(33 \%)$ & \\
\hline 2 & $6(46 \%)$ & $7(54 \%)$ & \\
\hline 3 & $14(70 \%)$ & $6(30 \%)$ & \\
\hline 4 & $10(83 \%)$ & $2(17 \%)$ & \\
\hline BMI groups & & & 0.25 \\
\hline$<30$ & $41(68 \%)$ & $19(32 \%)$ & \\
\hline$\geq 30$ & $1(33 \%)$ & $2(67 \%)$ & \\
\hline Sex & & & 0.27 \\
\hline Male & $28(70 \%)$ & $12(30 \%)$ & \\
\hline Female & $14(61 \%)$ & $9(39 \%)$ & \\
\hline Muscle $\mathbf{C M}^{2}$ & & & 0.28 \\
\hline$<$ Median & $24(73 \%)$ & $9(26 \%)$ & \\
\hline$\geq$ Median & $18(60 \%)$ & $12(40 \%)$ & \\
\hline Sarcopenia & & & 0.59 \\
\hline No & $21(70 \%)$ & $9(30 \%)$ & \\
\hline Yes & $21(64 \%)$ & $12(36 \%)$ & \\
\hline Charlson & & & 0.66 \\
\hline$<3$ & $34(68 \%)$ & $16(32 \%)$ & \\
\hline$\geq 3$ & $8(61 \%)$ & $5(39 \%)$ & \\
\hline
\end{tabular}

Univariate analysis for each study variable with corresponding P-values for the occurrence of postoperative complications (Clavien-dindo $\geq 2$ ), calculated by Chisquare, Likelihood ratio or Fisher's Exact test.

Muscle $\mathrm{CM}^{2}$ was defined as lower or higher than the median (men: $<154.5 \mathrm{~cm}^{2} / \mathrm{m}^{2}$ and $\geq 154.5 \mathrm{~cm}^{2} / \mathrm{m}^{2}$ woman $<103.3 \mathrm{~cm}^{2} / \mathrm{m}^{2}$ and $\left.\geq 103.3 \mathrm{~cm}^{2} / \mathrm{m}^{2}\right)$, Muscle attenuation was defined as higher or lower than the media value $(<34.1 \mathrm{HU}$ or $\geq 34.1 \mathrm{HU}$ ). differences in age. After additional adjustment for ASA, only age $\geq 70$ ( $\mathrm{p}=0.05$, OR 3.4, 95\%CI 1.0-11.5) remained significant, whilst ASA $\geq 3$ approached significant levels $(\mathrm{p}=0.08$, OR $8.5,95 \% \mathrm{CI}$ $0.8-94.5)$. MUST $\geq 2$ ( $\mathrm{p}=0.12$, OR 4.1, 95\%CI 0.7-24.7) and muscle attenuation $(\mathrm{p}=0.18$, OR $0.5,95 \% \mathrm{CI} 0.1-1.4)$ were insignificant in multivariable analysis. All multivariable models showed sarcopenia ( $\mathrm{p} \geq 0.66$ ) to be insignificant (Table 4 ).

\section{Discussion}

Our study shows a high prevalence of sarcopenia (52\%) in patients who have to undergo colorectal surgery, but failed to show a significant association with post-operative complications. In contrast, MUST $\geq 2$ and lower muscle attenuation were univariately associated with postoperative complications. However, when including both measures in multivariable analyses, muscle attenuation failed to show a significant association with postoperative complications in addition to MUST.

Malnutrition as measured with a variety of validated malnutrition screening tools has shown to be a predictor for worse outcome after colorectal, gastric, and general abdominal surgery [2-5,23]. More recently, body composition measurement through CT image analysis has become increasingly common. Several studies previously showed a relationship between CT-measured sarcopenia and increased post-operative morbidity and mortality following colorectal resection [10-12,18]. A number of studies have investigated the relationship between CT-measured sarcopenia and outcome after hepatocellular carcinoma (HCC) resection and the resection of colorectal liver metastasis. These studies also showed higher postoperative morbidity in sarcopenia patients [12-14]. However, not all studies support these findings [16,17]. Tegels et al. found a high prevalence of sarcopenia in gastric cancer patients, but no association with worse outcome [16]. In addition, Lodewick et al. found that obesity and sarcopenic obesity did not worsen disease-free survival, overall survival or complication rates after partial liver resection for colorectal liver metastasis [17]. Reisinger et al. [18] recently found that there was no significant association between sarcopenia alone and sepsis after CRC surgery, but postulated that a combined risk stratification using sarcopenia, functional compromise (measured by Groningen Frailty Index) and nutritional risk (measured by Short Nutritional Assessment Questionnaire) could successfully predict sepsis. Huang et al. [26] argued that sarcopenia should be defined as reduced muscle mass and reduced muscle strength, and/or physical performance, and showed that sarcopenia measured as reduced muscle mass and reduced physical performance (measured by gait speed and handgrip strength) was an independent predictor of post-operative complications after CRC surgery. The studies by Reisinger et al. and Huang et al. suggest the importance of physical function in the investigation of the role of sarcopenia in CRC.

Table 4

Multivariable analyses of all study parameters on post-operative complications clavien-dindo score $\geq 2$.

\begin{tabular}{|c|c|c|c|}
\hline Uncorrected & Alternate & Age corrected & Age + ASA corrected \\
\hline $\begin{array}{l}\text { MUST } \geq 2(P=0.02 \text { OR } \\
\quad 6.695 \% \text { CI } 1.4-30.9)\end{array}$ & $\begin{array}{l}\text { MUST } \geq 2(P=0.04 \text { OR } \\
5.195 \% \text { CI } 1.1-23.6)\end{array}$ & $\begin{array}{l}\text { Age } \geq 70(\mathrm{P}=0.02 \mathrm{OR} \\
4.095 \% \mathrm{CI} 1.2-13.3)\end{array}$ & Age $\geq 70(\mathrm{P}=0.05$ OR $3.495 \% \mathrm{CI} 1.0-11.5)$ \\
\hline $\begin{array}{l}\text { Sarcopenia }(P=0.91 \text { OR } \\
\quad 0.995 \% \mathrm{CI} 0.3-2.9)\end{array}$ & $\begin{array}{l}\text { Muscle Attenuation Index } \\
(\mathrm{P}=0.18 \text { OR } 0.5 \text { 95\%CI } 0.1-1.4)\end{array}$ & $\begin{array}{l}\text { MUST } \geq 2(P=0.03 \text { OR } \\
5.895 \% \text { CI } 1.1-29.6)\end{array}$ & $\mathrm{ASA} \geq 3(\mathrm{P}=0.08$ OR 8.5 95\%CI 0.8-94.5) \\
\hline & & $\begin{array}{l}\text { Sarcopenia }(P=0.70 \text { OR } \\
0.895 \% \text { CI } 0.2-2.7)\end{array}$ & MUST $\geq 2(P=0.12$ OR $4.195 \% C I$ 0.7-24.7) \\
\hline & & & Sarcopenia $(\mathrm{P}=0.66$ OR $0.895 \% \mathrm{CI} 0.2-2.7)$ \\
\hline
\end{tabular}

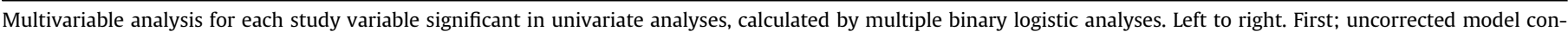

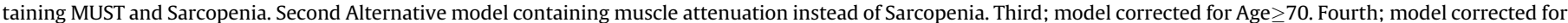
both Age $\geq 70$ and $A S A \geq 3$.

Muscle attenuation was defined as higher or lower than the media value $(<34.1 \mathrm{HU}$ or $\geq 34.1 \mathrm{HU})$. 
Muscle attenuation has been used as a measure for muscle density or function rather than muscle mass [20]. Although evidence is still limited, muscle attenuation may be independently prognostic of survival in patients with solid based tumors [24].This could possibly imply that muscle quality, i.e. muscle attenuation, may be of importance besides muscle quantity measurement, i.e. muscle volume measurements. Our study shows promising results regarding muscle attenuation, with a significant relationship with increased complications in univariate analysis. However, muscle attenuation did not reach statistical significance in predicting postoperative complications in addition to MUST. This might have been due to the small number of patients in the current study. Therefore, more research is needed on this topic, and we suggest the need for standardized muscle attenuation cutoff values. The causal relationship between sarcopenia, cachexia and post-operative morbidity is unknown. A correlation between preoperative inflammatory response and postoperative complications and mortality has previously been demonstrated [27-29]. Recently, Reisinger et al. [30] showed that low muscle mass in patients undergoing CRC surgery was associated with an increased post-operative inflammatory response. This may explain the high incidence of postoperative complications in sarcopenic patients.

The clinical implementation of CT sarcopenia measurement is time-consuming and therefore costly. Our study used pre-operative CT scans that were performed for oncological dissemination purposes and not for the purpose of sarcopenia measurement. This lead to a substantial percentage of CT scans being unusable for sarcopenia measurements (21\%) and therefor-limited statistical power. A strength of this study is that both the MUST screening and CT measurements were performed by only one researcher, reducing the influence of potential inter-observer differences. It must be noted that ASA $\geq 3$ has an excessively wide $95 \%$ confidence interval in our multivariate model (OR 8.5, 95\%CI 0.8-94.5). This is most likely due to the fact that this variable shows a substantial skewness with only one of 63 cases having an ASA $\geq 3$ without complications. This combined with a limited power consequent to the low number of outcome events causes this variable to have a profound impact on our multivariate models.

Our results suggest that CT-measured sarcopenia may have only little additional value over the MUST for the prediction of increased short-term post-operative morbidity after oncological colorectal surgery. It also underlines the importance of currently implemented easy-to-use nutritional screening tools (MUST) and raises the question of the evaluation of muscle quality versus quantity in body composition imaging. However, further population-wide research is needed to investigate role of sarcopenia for predicting outcome after colorectal surgery, and investigate the role of muscle attenuation measurements for the prediction of muscle function.

\section{Author contribution}

G Van der Kroft Data acquisition, analysis, writing manuscript; M Bours Writing Manuscript, Revision; M. Janssen-Heijnen Manuscript Revision, Statistical analysis; C van Berlo, Manuscript Revision; J Konsten, Conceptualization, manuscript revision. All authors All authors approved submission of this article.

\section{Funding}

MJL Bours is partly supported by grants from the Alpe d'HuZes Foundation of the Dutch Cancer Society (Grant No. UM-2012-5633) and from the 'Kankeronderzoekfonds Limburg' as part of Health
Foundation Limburg (Grant No. 00005739). No additional funding was required for the conduction of this study.

\section{Conflict of interest}

The authors declare no conflict of interest.

\section{References}

[1] Registratie NK. NKR (Nederlandse Kanker Registratie) cijfers. NKR; 2016.

[2] Schwegler I, von Holzen A, Gutzwiller JP, Schlumpf R, Muhlebach S, Stanga Z. Nutritional risk is a clinical predictor of postoperative mortality and morbidity in surgery for colorectal cancer. Br J Surg 2010:97(1):92-7.

[3] Guo W, Ou G, Li X, Huang J, Liu J, Wei H. Screening of the nutritional risk of patients with gastric carcinoma before operation by NRS 2002 and its relationship with postoperative results. J Gastroenterol Hepatol 2010;25(4): 800-3.

[4] Schiesser M, Muller S, Kirchhoff P, Breitenstein S, Schafer M, Clavien PA Assessment of a novel screening score for nutritional risk in predicting complications in gastro-intestinal surgery. Clin Nutr 2008;27(4):565-70.

[5] Kuppinger D, Hartl WH, Bertok M, Hoffmann JM, Cederbaum J, Kuchenhoff H et al. Nutritional screening for risk prediction in patients scheduled for abdominal operations. Br J Surg 2012;99(5):728-37.

[6] Kondrup J, Allison SP, Elia M, Vellas B, Plauth M, Educational, et al. ESPEN guidelines for nutrition screening 2002. Clin Nutr 2003;22(4):415-21.

[7] Sorensen J, Kondrup J, Prokopowicz J, Schiesser M, Krahenbuhl L, Meier R, et al. EuroOOPS: an international, multicentre study to implement nutritional risk screening and evaluate clinical outcome. Clin Nutr 2008;27(3): 340-9.

[8] Jebb SA. Incidence and recognition of malnutrition in hospital J. P. McWhirter and C. R. Pennington BMJ 1994; 308: 945-948. Clin Nut1 1994;13(4):267-8.

[9] Prado CM, Birdsell LA, Baracos VE. The emerging role of computerized tomography in assessing cancer cachexia. Curr Opin Support Palliat Care 2009;3(4):269-75.

[10] Lieffers JR, Bathe OF, Fassbender K, Winget M, Baracos VE. Sarcopenia is associated with postoperative infection and delayed recovery from colorectal cancer resection surgery. Br J Canc 2012;107(6):931-6.

[11] Prado CM, Lieffers JR, McCargar LJ, Reiman T, Sawyer MB, Martin L, et al Prevalence and clinical implications of sarcopenic obesity in patients with solid tumours of the respiratory and gastrointestinal tracts: a populationbased study. Lancet Oncol 2008;9(7):629-35.

[12] van Vledder MG, Levolger S, Ayez N, Verhoef C, Tran TC, Ijzermans JN. Body composition and outcome in patients undergoing resection of colorectal liver metastases. Br J Surg 2012;99(4):550-7.

[13] Peng PD, van Vledder MG, Tsai S, de Jong MC, Makary M, Ng J, et al. Sarcopenia negatively impacts short-term outcomes in patients undergoing hepatic resection for colorectal liver metastasis. HPB (Oxford) 2011;13(7): 439-46.

[14] Harimoto N, Shirabe K, Yamashita YI, Ikegami T, Yoshizumi T, Soejima Y, et al. Sarcopenia as a predictor of prognosis in patients following hepatectomy for hepatocellular carcinoma. Br J Surg 2013;100(11):1523-30.

[15] Harimoto N, Yoshizumi T, Shimokawa M, Sakata K, Kimura K, Itoh S, et al. Sarcopenia is a poor prognostic factor following hepatic resection in patients 70 years of age and older with hepatocellular carcinoma. Hepatol Res 2016;46(12):1247-55.

[16] Tegels JJ, van Vugt JL, Reisinger KW, Hulsewe KW, Hoofwijk AG, Derikx JP, et al. Sarcopenia is highly prevalent in patients undergoing surgery for gastric cancer but not associated with worse outcomes. J Surg Oncol 2015;112(4): 403-7.

[17] Lodewick TM, van Nijnatten TJ, van Dam RM, van Mierlo K, Dello SA Neumann UP, et al. Are sarcopenia, obesity and sarcopenic obesity predictive of outcome in patients with colorectal liver metastases? HPB (Oxford) 2015; 17(5):438-46.

[18] Reisinger KW, van Vugt JL, Tegels JJ, Snijders C, Hulsewe KW, Hoofwijk AG, et al. Functional compromise reflected by sarcopenia, frailty, and nutritiona depletion predicts adverse postoperative outcome after colorectal cancer surgery. Ann Surg 2015;261(2):345-52.

[19] Ross R. Advances in the application of imaging methods in applied and clinical physiology. Acta Diabetol 2003;40(Suppl. 1):S45-50.

[20] Aubrey J, Esfandiari N, Baracos VE, Buteau FA, Frenette J, Putman CT, et al Measurement of skeletal muscle radiation attenuation and basis of its biological variation. Acta Physiol (Oxf) 2014;210(3):489-97.

[21] Charlson M, Szatrowski TP, Peterson J, Gold J. Validation of a combined comorbidity index. J Clin Epidemiol 1994;47(11):1245-51.

[22] Dindo D, Demartines N, Clavien PA. Classification of surgical complications: a new proposal with evaluation in a cohort of 6336 patients and results of a survey. Ann Surg 2004;240(2):205-13.

[23] van der Kroft G, Janssen-Heijnen MLG, van Berlo CLH, Konsten JLM. Evaluation of nutritional status as an independent predictor of post-operative complications and morbidity after gastro-intestinal surgery. Clinical Nutrition ESPEN 2015;10(4):e129-33. 
[24] Martin L, Birdsell L, Macdonald N, Reiman T, Clandinin MT, McCargarLJ, etal. Cancer cachexia in the age of obesity: skeletal muscle depletion is a powerful prognostic factor, independent of body mass index. J Clin Oncol 2013;31(12):1539-47.

[25] Fearon K, Strasser F, Anker SD, Bosaeus I, Bruera E, Fainsinger RL, et al. Definition and classification of cancer cachexia: an international consensus. Lancet Oncol 2011;12(5):489-95.

[26] Huang DD, Wang SL, Zhuang CL, Zheng BS, Lu JX, Chen FF, et al. Sarcopenia, as defined by low muscle mass, strength and physical performance, predicts complications after surgery for colorectal cancer. Colorectal Dis 2015;17(11): 0256-64.

[27] Moyes LH, Leitch EF, McKee RF, Anderson JH, Horgan PG, McMillan DC. Preoperative systemic inflammation predicts postoperative infectious complications in patients undergoing curative resection for colorectal cancer. Br J Canc 2009;100(8):1236-9.

[28] Ishizuka M, Nagata $H$, Takagi $K$, Horie $T$, Kubota K. Inflammation-based prognostic score is a novel predictor of postoperative outcome in patients with colorectal cancer. Ann Surg 2007;246(6):1047-51.

[29] McMillan DC. The systemic inflammation-based Glasgow Prognostic Score: a decade of experience in patients with cancer. Cancer Treat Rev 2013;39(5): 534-40.

[30] Reisinger KW, Derikx JP, van Vugt JL, Von Meyenfeldt MF, Hulsewe KW, Olde Damink SW, et al. Sarcopenia is associated with an increased inflammatory response to surgery in colorectal cancer. Clin Nutr 2016;35(4): 924-7. 